\title{
Matched-pair analysis: identification of factors with independent influence on the development of PTLD after kidney or liver transplantation
}

\author{
Lisa Rausch ${ }^{1}$, Christian Koenecke ${ }^{2}$, Hans-Friedrich Koch ${ }^{1}$, Alexander Kaltenborn ${ }^{1,3}$, Nikos Emmanouilidis ${ }^{1,4}$,
} Lars Pape ${ }^{5}$, Frank Lehner ${ }^{4}$, Viktor Arelin ${ }^{1,6}$, Ulrich Baumann ${ }^{5}$ and Harald Schrem ${ }^{1,4^{*}}$

\begin{abstract}
Background: Post-transplant lymphoproliferative disorder (PTLD) adversely affects patients' long-term outcome. Methods: The paired $t$ test and McNemar's test were applied in a retrospective 1:1 matched-pair analysis including 36 patients with PTLD and 36 patients without PTLD after kidney or liver transplantation. Matching criteria were age, gender, indication, type of transplantation, and duration of follow-up. All investigated PTLD specimen were histologically positive for EBV. Risk-adjusted multivariable regression analysis was used to identify independence of risk factors for PTLD detected in matched-pair analysis. The resultant prognostic model was assessed with ROC-curve analysis.

Results: Patients suffering with PTLD had shorter mean survival ( $p=0.004)$, more episodes of CMV infections or reactivations ( $p=0.042)$, and fewer recipient HLA A2 haplotypes $(p=0.007)$, a tacrolimus-based immunosuppressive regimen ( $p=0.052)$ and higher dosages of tacrolimus at hospital discharge (Tac dosage) $(p=0.052)$. Significant independent risk factors for PTLD were recipient HLA A2 (OR $=0.07,95 \% \mathrm{Cl}=0.01-0.55, p=0.011$ ), higher Tac dosages $(\mathrm{OR}=1.29,95 \% \mathrm{Cl}=1.01-1.64, p=0.040)$, and higher numbers of graft rejection episodes $(\mathrm{OR}=0.38$, $95 \% \mathrm{Cl}=0.17-0.87, p=0.023)$. The following prognostic model for the prediction of PTLD demonstrated good model fit and a large area under the ROC curve (0.823): PTLD probability in $\%=\operatorname{Exp}(y) /(1+\operatorname{Exp}(y))$ with $y=0.671$ $-1.096 \times$ HLA A2-positive recipient $+0.151 \times$ Tac dosage $-0.805 \times$ number of graft rejection episodes.

Conclusions: This study suggests prognostic relevance for recipient HLA A2, CMV, and EBV infections or reactivations and strong initial tacrolimus-based immunosuppression. Patients with risk factors may benefit from intensified screening for PTLD.
\end{abstract}

Keywords: Mortality, Immunosuppression, Tacrolimus, CMV infection, Human leukocyte antigen

\section{Background}

Post-transplant lymphoproliferative disorders (PTLD) are a heterogeneous group of diseases [1]. A clear definition is difficult since PTLD include a wide spectrum from lymphoid hyperplasia, like mononucleosis, to atypical lymphoid hyperplasia with beginning effacement of

\footnotetext{
* Correspondence: schrem.harald@mh-hannover.de

${ }^{1}$ Core Facility Quality Management \& Health Technology Assessment in Transplantation, Integrated Research and Treatment Center Transplantation (IFB-Tx), Hannover Medical School, Hannover, Germany

${ }^{4}$ General, Visceral and Transplant Surgery, Hannover Medical School, Carl-Neuberg-Str. 1, 30625 Hannover, Germany

Full list of author information is available at the end of the article
}

normal tissue architecture, to an infiltrative type of polyclonal to monoclonal lymphoma [2, 3]. Despite these taxonomical imprecisions, PTLD is clearly a serious and life-threatening complication after transplantation with a high mortality rate of 30-60\% [4].

The underlying disease leading to transplantation might have an influence on the risk of developing PTLD [5]. It was reported that patients under the age of 10 , as well as patients over 60 years of age, are more likely to develop PTLD [1, 6-8]. Furthermore, pre-transplant malignancy is supposed to increase the risk of PTLD $[1,9,10]$. Human leukocyte antigen (HLA) types HLA-A2, HLA-A11, HLA- 
B5, HLA-B18, HLA-B21, and HLA-B35 in transplant recipients as well as HLA-B40 group in EBV-seropositive and HLA-B8 in EBV-seronegative patients were described to be associated with an increased risk for PTLD, whereas HLA-A3 and HLA-DR7 appear to decrease the risk [11-13]. Beside the recipients' HLA status, the donors' HLA typing result as well as the matching or mismatching of both seems to have an influence on the development of PTLD [1, 4, 14-16].

There is some evidence that the type and intensity of immunosuppression influences the risk of PTLD $[7-9,17-23]$.

The majority of PTLDs are associated with EBV infection [1, 24-29], and thus the risk for PTLD depends on the donor's and recipient's EBV status [1, 24, 29, 30]. In conjunction with this observation, it has been described that antiviral agents, such as ganciclovir, aciclovir, and foscarnet, may be useful for therapy and prophylaxis of EBV-related PTLD [1, 31-34].

Coexisting CMV infection might be a risk factor for PTLD [7, 35, 36]. However, this association has not been confirmed yet $[5,37,38]$. Infections with the hepatitis $\mathrm{C}$ virus and human herpes virus 8 have also been described as risk factors for PTLD [1, 36, 39, 40].

This study aims to evaluate the relevance of risk factors for PTLD development in adult and pediatric patients after primary kidney or liver transplantation independent of age, gender, indication for transplantation, type of transplantation, year of transplantation, and duration of follow-up by using these factors as matching criteria for a matched-pair analysis.

\section{Methods}

\section{Setting}

A university hospital in Germany provides the setting within the Eurotransplant community.

\section{Study type and study population}

This is a single-center retrospective observational 1:1 matched-pair analysis based on 2897 patients who underwent primary liver transplantation between 01.01.1983 and 31.12.2012, as well as 1895 patients who underwent primary kidney transplantation between 01.01 .2000 and 31.12.2012 at Hannover Medical School. Combined transplants were excluded due to a lack of adequate matching partners.

\section{Definition of matching criteria}

Each analyzed case with PTLD during follow-up was matched with one non-PTLD case applying the matching criteria age at transplantation, gender, indication for transplantation, type of transplantation, year of transplantation, and duration of post-transplant follow-up. In non-PTLD patients, the duration of follow-up for matching was defined as time to PTLD diagnosis of the matching partner.

\section{Definition of analyzed variables}

Concerning donor and recipient HLA status, we only considered the donors' HLA of the actual transplanted organ at PTLD diagnosis, which may be relevant in cases with multiple transplants during follow-up $(n=5)$. The same principle was applied to the matching partners without PTLD with subsequent transplants during follow-up $(n=6)$ : the donors' HLA at the equivalent time point to the diagnosis of PTLD in the corresponding partner was considered.

Borderline changes in the transplanted organ were categorized according to the Banff classification and classified as graft rejections for the purpose of this study, because these changes were typically treated with high dose steroids, just as in acute graft rejection which is common practice in many centers [41].

In the absence of an explicit proof of infection, children under the age of 1 year were considered seronegative for viral infections as maternal antibodies may give false positive antibody status [21].

Quantitative data on immunosuppressive therapy of our patients was collected from hospital discharge after transplantation until the time of PTLD diagnosis or equivalent time periods for the non-PTLD matching partners. The duration of given immunosuppressive drugs in months and all changes of the type of immunosuppression were analyzed, and percentages of the follow-up time with either ciclosporine-based or tacrolimus-based immunosuppression were calculated. If a patient was not receiving tacrolimus, ciclosporine, etc., the value was set to zero.

\section{Statistical methods}

In matched-pair analysis, all continuous variables were analyzed using the paired $t$ test while binominal variables were analyzed using McNemar's test. Multivariable principal component analysis was used to understand the underlying data structure and to define uncorrelated variables for prognostic score design by avoiding multicollinearity in regression (Fig. 1). After exclusion of multicollinearity, all variables with an alpha-error $<0.200$ in univariable analyses (paired $t$ test for continuous variables and McNemar's test for binominal variables) were included into multivariable conditional logistic regression analysis for binary matched pairs as described by Agresti [42] with the goal to develop a regression model for the prediction of PTLD and to identify significant risk-adjusted independent risk factors for PTLD. Model fit was assessed for regression models using HosmerLemeshow's chi-square test. ROC-curve analysis was performed to calculate the sensitivity and specificity of the derived regression model for the prediction of PTLD 


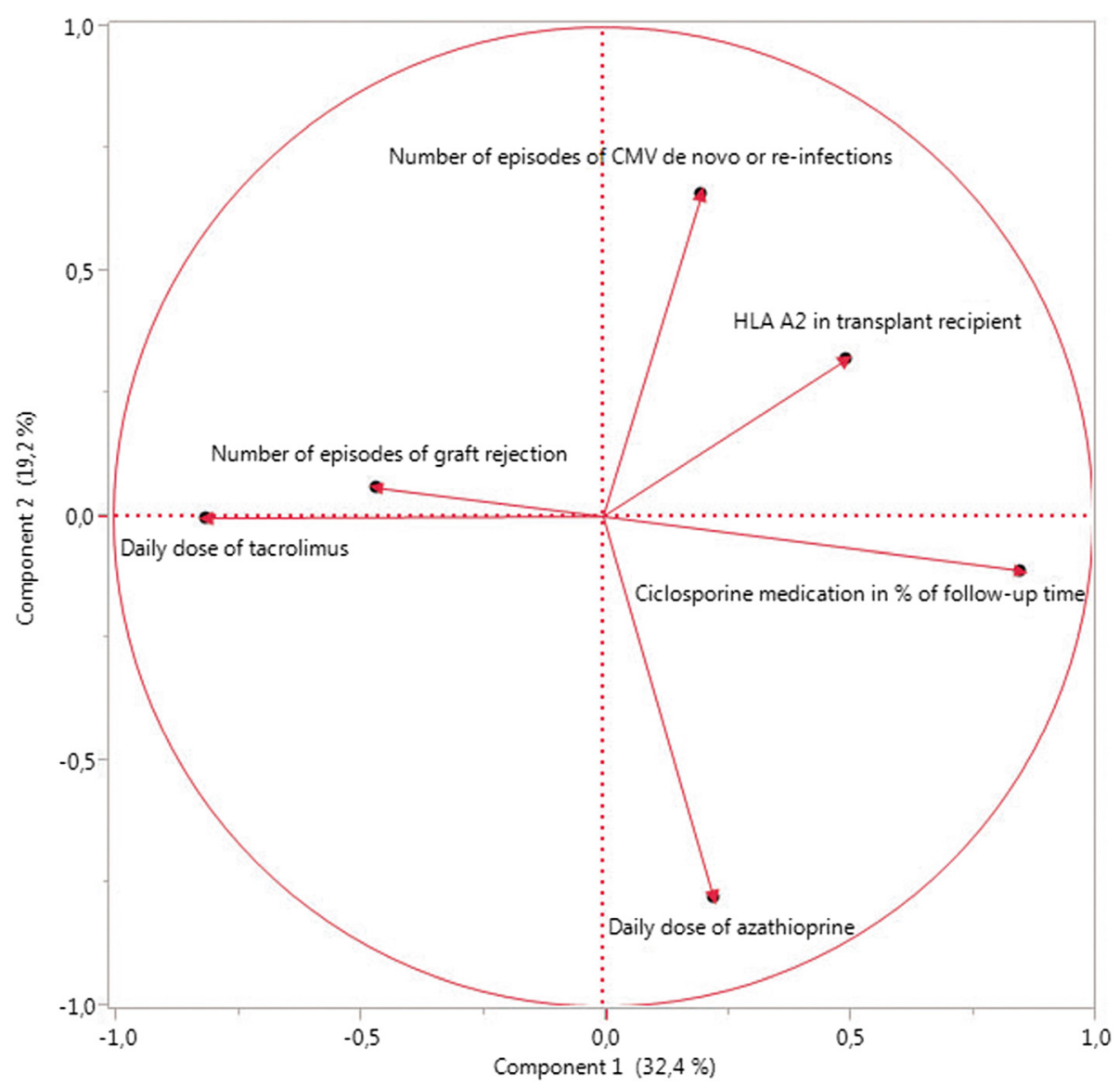

Fig. 1 Shown is the result of principal component analysis of analyzed risk factors prior to inclusion into multivariable regression models. This result demonstrates lack of relevant multicollinearity of these factors

$[43,44]$. Determination of the area under the ROCcurve (AUROC) was used to assess the potential clinical usefulness of the final prediction model $[43,44]$ derived with the logit link function.

All $p$ values $<0.05$ were defined as significant. Analyses were performed using $\mathrm{JMP}^{\bullet}$ software, version 11, from SAS Institute Inc., Cary, NC, USA.

\section{Results}

\section{Identification of PTLD cases and their inclusion into matched-pair analysis}

A total of 41 cases with PTLD were identified. Thirty-six of these 41 patients with PTLD were included into the matched-pair analysis, with 16 of them being primary kidney-transplanted patients and 20 primary liver transplanted patients. Five patients with PTLD were excluded due to the lack of available data on important risk factors or inability to find an appropriate matching case without PTLD during follow-up.
Within the group of 16 kidney-transplanted patients, nine were female and seven were male with nine being transplanted as a child and seven as an adult. The median age at the transplantation of kidney-transplanted patients with PTLD was 14.4 years (mean age 23.6 years) whereas the median age of their non-PTLD counterparts was 15.6 years (mean age 26.6). All of them were transplanted between 2000 and 2010. The underlying diseases leading to transplantation form a heterogeneous group of diseases, varying between different types of glomerulonephritis to kidney dysplasia, autosomal dominant polycystic disease, hemolytic-uremic syndrome, and others.

Within the group of 20 liver-transplanted patients, five were female and 15 were male with 12 of them being transplanted as a child and eight being transplanted as an adult. The median age at transplantation in the PTLD group was 5.5 years (mean age 21.2 years) as compared to 7.8 years (mean age 21.3 years) in the non-PTLD group. Here, the underlying diseases leading to transplantation 
were biliary atresia in many cases and less frequently primary sclerosing cholangitis, viral-related cirrhosis and acute liver failure.

The mean differences of the date of transplantation and the age at transplantation between matches were 0.02 days (standard error 103.8 days, $p=0.147$; paired $t$ test) and 0.04 years (standard error 0.33 years, $p=0.901$; paired $t$ test), respectively. All other matching criteria were $100 \%$ identical matches.

\section{Clinicopathological characteristics of analyzed PTLD cases} Within 36 analyzed PTLD cases, 16 underwent kidney transplantation and 20 underwent liver transplantation. Twenty-one of 36 patients were transplanted as children (age $<17$ years) and 15 as adults, with 19 of them being diagnosed for PTLD during childhood (8 kidneytransplanted cases and 11 liver-transplanted cases) versus 17 adult PLTD patients. The mean time to PTLD diagnosis was 3.8 years, and the median age of the patients at PTLD diagnosis was 15.7 years (range $0.8-70.8$ years, mean 26.1 years).

Overall mortality during follow-up was $36.1 \%$ in PTLD patients with a mean survival of 294 days after PTLD diagnosis (median 119 days, range 11-953 days). Eleven of the 13 patients who died after PTLD diagnosis had a late PTLD (>365 days after transplantation) and one had a very early PTLD ( $<183$ days after transplantation). The mean age at PTLD diagnosis of these 13 PTLD cases that subsequently died was 32.7 years (median 43.4 years, range 2.2-63.8 years). All of them died after 01.01.2000, and 5 of these patients died after 01.01.2010. Twelve of these 13 patients had a monomorphic PTLD while 8 of them had PTLD disease classified as diffuse large B-cell lymphoma. Ten of the deceased patients had extranodal disease with five patients suffering from CNS involvement and three patients having a primary CNS lymphoma. Six of these 13 patients were treated with rituximab with or without chemotherapy and five patients were treated with radiotherapy. In six of 11 patients who subsequently died, immunosuppressive therapy was changed after PTLD diagnosis while in five of 11 patients who died received antiviral therapy.

The distributions of the clinicopathological characteristics of 36 analyzed PTLD cases are summarized in Table 1.

\section{Survival in PTLD versus matched non-PTLD patients}

Only in one pair the non-PTLD patient died within the timeframe in which the PTLD-match was still alive. In contrast, 11 PTLD patients died during follow-up while their non-PTLD matching partners continued to survive ( $p=0.004$, McNemar's test) (Table 2). Mean survival after the transplantation of PTLD patients (7.74 years) was significantly shorter as compared to the matched
non-PTLD partners (9.98 years) ( $p=0.004$, paired $t$ test) (Table 3, Fig. 2).

\section{Significant risk factors for PTLD development in matched-pair analysis}

The number of episodes of CMV de novo infections or reactivations showed a significant difference between PTLD cases (mean: 1.47) and their non-PTLD matching partners (mean: 0.75$)(p=0.042$, paired $t$ test) (Table 3, Fig. 3).

The recipients' HLA A2 was significantly more frequent in the non-PTLD matching partners. In 10 out of 19 analyzed pairs, the PTLD patient was negative for HLA A2 while the matching partners were HLA A2 positive and only in one discordant pair, we found the opposite result ( $p=0.007$, McNemar's test) (Table 2).

Immunosuppression with tacrolimus at the time of hospital discharge after transplantation was associated with later development of PTLD ( $p=0.052$; McNemar's test). In ten pairs, the patient with PTLD was treated with tacrolimus at hospital discharge while their respective matching partners received ciclosporine-based immunosuppression instead. In three discordant cases, the opposite was the case (Table 2). The mean daily dose of tacrolimus at hospital discharge was significantly higher within the PTLD group (3.74 $\mathrm{mg}$ ) as compared to their non-PTLD matching partners $(1.62 \mathrm{mg})(p=0.052$, paired $t$ test) (Table 3, Fig. 4). However, blood levels of tacrolimus or ciclosporine (trough blood level as well as blood level 2 hours after oral intake) at hospital discharge did not show to be significantly different between matched pairs (Table 3). Immunosuppressive induction therapy with anti-thymocyte globulin (ATG), basiliximab, and daclizumab did not differ significantly between PTLD and non-PTLD patients. In matched-pair analysis, an equal number of discordant pairs resolved in a non-significant $p$ value for immunosuppressive induction therapies either with basiliximab or daclizumab (Table 2).

All other analyzed risk factors did not show any statistically significant differences between the PTLD cases and their matched controls (Tables 2 and 3). In particular, the recipients' EBV serology status at transplantation was not significantly different between PTLD cases and their matching partners $(p>0.05$, McNemar's test). In four pairs, the PTLD patient was EBV IgG negative at transplantation and the matching non-PTLD partner was EBV IgG positive, whereas in two pairs, the opposite was observed with the PTLD case EBV IgG positive and the matching partner EBV IgG negative at transplantation ( $p=0.414$; McNemar's test). Analysis of ganciclovir or valganciclovir treatment after transplantation revealed seven matching pairs where the PTLD patient did not 
Table 1 Clinicopathological characteristics of all PTLD patients

\begin{tabular}{|c|c|}
\hline Variable & Distribution \\
\hline Age at transplantation in years & $\begin{array}{l}\text { Median: } 12.7(0.4-65.4) \\
\text { mean: } 22.3\end{array}$ \\
\hline Time to diagnosis after transplantation in years & $\begin{array}{l}\text { Median: } 2.1(0.3-19) ; \\
\text { mean: } 3.8\end{array}$ \\
\hline Age at PTLD diagnosis in years & $\begin{array}{l}\text { Median: } 15.7(0.8-70.8) \\
\text { mean: } 26.1\end{array}$ \\
\hline Age $>60$ years at PTLD diagnosis & $n=4(11.1 \%)$ \\
\hline Age $<10$ years at PTLD diagnosis & $n=14(38.9 \%)$ \\
\hline Age $<5$ years at PTLD diagnosis & $n=11(30.6 \%)$ \\
\hline Late PTLD (>365 days after Tx) & $n=24(66.7 \%)$ \\
\hline Very early PLTD (<183 days after Tx) & $n=4(11.1 \%)$ \\
\hline Ciclosporine at PTLD diagnosis & $n=15(41.7 \%)$ \\
\hline Tacrolimus at PTLD diagnosis & $n=16(44.4 \%)$ \\
\hline CNI-free immunosuppression at PTLD diagnosis & $n=5(13.9 \%)$ \\
\hline Mycophenolat at PTLD diagnosis & $n=19(52.8 \%)$ \\
\hline Steroids at PTLD diagnosis & $n=29(80.6 \%)$ \\
\hline $\begin{array}{l}\text { Steroid-free immunosuppression at PTLD } \\
\text { diagnosis }\end{array}$ & $n=7(19.4 \%)$ \\
\hline mTOR inhibitors at PTLD diagnosis & $n=1(2.8 \%)$ \\
\hline $\begin{array}{l}\text { Number of graft rejections prior to PTLD } \\
\text { diagnosis }\end{array}$ & $\begin{array}{l}\text { Median: } 0(0-2) \\
\text { mean: } 0.44\end{array}$ \\
\hline Number of graft rejections after PTLD diagnosis & $\begin{array}{l}\text { Median: } 0(0-1) \\
\text { mean: } 0.25\end{array}$ \\
\hline Polymorphic PTLD & $n=5(13.9 \%)$ \\
\hline Monomorphic PTLD & $n=28(77.8 \%)$ \\
\hline Pure B cell neoplasm & $n=29(80.6 \%)$ \\
\hline Diffuse large B cell neoplasm & $n=20(55.6 \%)$ \\
\hline CD20 expression in tumor & $n=32(88.9 \%)$ \\
\hline $\begin{array}{l}\text { EBV latent membrane protein or EBV-encoded } \\
\text { RNA in tumor cells }\end{array}$ & $\begin{array}{l}n=26\left(100.0 \%^{\mathrm{a}},\right. \\
10 \text { cases missing data })\end{array}$ \\
\hline Detection of monoclonal disease & $\begin{array}{l}n=9\left(52.9 \%^{\mathrm{a}},\right. \\
19 \text { cases missing data })\end{array}$ \\
\hline Extranodal disease & $n=24(66.7 \%)$ \\
\hline Graft organ involvement & $n=4(11.1 \%)$ \\
\hline CNS involvement & $n=7(19.4 \%)$ \\
\hline Primary CNS lymphoma & $n=4(11.1 \%)$ \\
\hline Bone marrow involvement & $n=6(16.7 \%)$ \\
\hline Gastro-intestinal involvement & $n=14(38.9 \%)$ \\
\hline Lung involvement & $n=3(8.3 \%)$ \\
\hline Skin involvement & $n=0(0.0 \%)$ \\
\hline Number of sites involved & $\begin{array}{l}\text { Median: } 2(1-6) ; \\
\text { mean: } 2.5\end{array}$ \\
\hline Stage IV disease & $n=25(69.4 \%)$ \\
\hline B-symptoms at PTLD diagnosis & $n=4(11.1 \%)$ \\
\hline $\begin{array}{l}\text { Lactate dehydrogenase elevated at PTLD } \\
\text { diagnosis }\end{array}$ & $\begin{array}{l}n=23\left(71.9 \%^{\mathrm{a}}\right. \\
4 \text { cases missing data })\end{array}$ \\
\hline Hypoalbuminemia at PTLD diagnosis & $\begin{array}{l}n=17\left(65.4 \%^{\mathrm{a}}\right. \\
10 \text { cases missing data })\end{array}$ \\
\hline
\end{tabular}

Table 1 Clinicopathological characteristics of all PTLD patients (Continued)

\begin{tabular}{|c|c|}
\hline$E B V \lg G$ at $T x$ & $\begin{array}{l}n=14\left(45.2 \%^{\mathrm{a}}\right. \\
5 \text { cases missing data) }\end{array}$ \\
\hline EBV $\lg M$ at $T x$ & $\begin{array}{l}n=1(3.3 \% \\
6 \text { cases missing data })\end{array}$ \\
\hline EBV serology or DNA positive at PTLD diagnosis & $\begin{array}{l}n=31\left(100.0 \% \%^{\mathrm{a}}\right. \\
5 \text { cases missing data) }\end{array}$ \\
\hline EBV DNA at PTLD diagnosis & $\begin{array}{l}n=29\left(96.7 \%^{\mathrm{a}},\right. \\
6 \text { cases missing data })\end{array}$ \\
\hline EBV IgG at PTLD diagnosis & $\begin{array}{l}n=21(77.8 \% \text { a } \\
9 \text { cases missing data })\end{array}$ \\
\hline CMV IgG at Tx & $\begin{array}{l}n=12\left(35.3 \%^{\mathrm{a}},\right. \\
2 \text { cases missing data) }\end{array}$ \\
\hline CMV IgM at Tx & $\begin{array}{l}n=3\left(9.7 \%{ }^{\mathrm{a}},\right. \\
5 \text { cases missing data })\end{array}$ \\
\hline CMV pp65 at Tx & $\begin{array}{l}n=1\left(3.8 \%{ }^{\mathrm{a}}\right. \\
10 \text { cases missing data })\end{array}$ \\
\hline $\begin{array}{l}\text { CMV serology or DNA positive at PTLD } \\
\text { diagnosis }\end{array}$ & $\begin{array}{l}n=23\left(100 \%^{\mathrm{a}},\right. \\
13 \text { cases missing data })\end{array}$ \\
\hline CMV pp65 at PTLD diagnosis & $\begin{array}{l}n=1(4.2 \% \text { a } \\
12 \text { cases missing data })\end{array}$ \\
\hline CMV DNA at PTLD diagnosis & $\begin{array}{l}n=4\left(22.2 \%{ }^{\mathrm{a}},\right. \\
18 \text { cases missing data) }\end{array}$ \\
\hline CMV IgM at PTLD diagnosis & $\begin{array}{l}n=7(30.4 \% \\
13 \text { cases missing data })\end{array}$ \\
\hline CMV IgG at PTLD diagnosis & $\begin{array}{l}n=21\left(77.8 \% \%^{\mathrm{a}}\right. \\
9 \text { cases missing data })\end{array}$ \\
\hline
\end{tabular}

Shown are the distributions of clinicopathological characteristics of 36 analyzed PTLD cases

Tx transplantation, CNI-free calcineurin-inhibitor-free, EBV Epstein-Barr virus, CMV cytomegalovirus ${ }^{\text {aOf }}$ evaluated cases

receive ganciclovir or valganciclovir when the nonPTLD patient did, whereas in nine matching pairs, this was the opposite ( $p=0.617$; McNemar's test).

\section{Independent risk factors for PTLD development in multivariable conditional logistic regression}

Multivariable conditional regression analysis revealed that HLA A2 in the transplant recipient (odds ratio (OR) $0.07,95 \%$ CI $0.01-0.55, p=0.011$ ), the level of tacrolimus dosing at hospital discharge after transplantation (OR 1.29, $95 \%$ CI 1.01-1.64, $p=0.040$ ) and the number of graft rejection episodes (OR 0.38, $95 \%$ CI $0.17-0.87, p=0.023$ ) were independent significant risk factors after risk adjustment for the matching criteria and the included variables with $p$ values $<0.200$ in univariable analyses (Tables 2 and 3 ). Multivariable principal component analysis demonstrated lack of multicollinearity between these variables (Fig. 1). 
Table 2 Matched-pair analysis for binominal variables

\begin{tabular}{|c|c|c|c|c|c|c|}
\hline \multirow[t]{2}{*}{ Variables $(+) /(-)^{a}$} & \multirow{2}{*}{$\begin{array}{l}\text { Nr. of analyzed } \\
\text { matched } \\
\text { pairs in } \%\end{array}$} & \multicolumn{2}{|c|}{ Concordant pairs } & \multicolumn{2}{|c|}{ Discordant pairs } & \multirow[t]{2}{*}{$p$ value $^{\mathrm{b}}$} \\
\hline & & $\begin{array}{l}\text { Combination } \\
\text { PTLD (+) and } \\
\text { non-PTLD (+) }\end{array}$ & $\begin{array}{l}\text { Combination } \\
\text { PTLD (-) and } \\
\text { non-PTLD (-) }\end{array}$ & $\begin{array}{l}\text { Combination } \\
\text { PTLD }(-) \text { and } \\
\text { non-PTLD (+) }\end{array}$ & $\begin{array}{l}\text { Combination } \\
\text { PTLD (+) and } \\
\text { non-PTLD (-) }\end{array}$ & \\
\hline Death & 100.0 & 2 & 22 & 1 & 11 & 0.004 \\
\hline Subsequent re-transplants & 100.0 & 1 & 26 & 5 & 4 & 0.739 \\
\hline Living Donor & 100.0 & 4 & 18 & 5 & 9 & 0.285 \\
\hline $\mathrm{BMI}>30 \mathrm{~kg} / \mathrm{m}^{2}$ & 100.0 & 0 & 32 & 2 & 1 & 0.564 \\
\hline Diabetes & 100.0 & 0 & 32 & 2 & 2 & 1.000 \\
\hline Alcohol abuse & 100.0 & 0 & 34 & 2 & 0 & n.d. \\
\hline Active Smoking & 100.0 & 0 & 31 & 2 & 3 & 0.655 \\
\hline COPD & 100.0 & 0 & 35 & 1 & 0 & n.d. \\
\hline Recipient EBV IgG at Tx & 86.1 & 12 & 13 & 4 & 2 & 0.414 \\
\hline Recipient CMV IgG at Tx & 91.7 & 9 & 15 & 6 & 3 & 0.317 \\
\hline Donor CMV lgG at Tx & 97.2 & 13 & 8 & 5 & 9 & 0.285 \\
\hline Recipient Anti-HCV at Tx & 61.1 & 0 & 22 & 0 & 0 & n.d. \\
\hline Anti-CMV treatment after Tx & 100.0 & 10 & 9 & 7 & 10 & 0.467 \\
\hline Ganciclovir/valganciclovir after Tx & 100.0 & 9 & 11 & 7 & 9 & 0.617 \\
\hline Pre-transplant malignancy & 100.0 & 2 & 34 & 0 & 0 & 1.000 \\
\hline Pre-transplant HCC & 100.0 & 2 & 34 & 0 & 0 & 1.000 \\
\hline Non-PTLD malignancy after Tx & 100.0 & 0 & 31 & 2 & 3 & 0.655 \\
\hline Breast cancer after $T x$ & 100.0 & 0 & 35 & 0 & 1 & n.d. \\
\hline Pre-transplant dialysis & 100.0 & 12 & 20 & 2 & 2 & 1.000 \\
\hline Donor HLA A26, B38 & 75.0 & 0 & 25 & 0 & 2 & n.d. \\
\hline Donor HLA A1 & 75.0 & 1 & 15 & 5 & 6 & 0.763 \\
\hline Donor HLA B8 & 75.0 & 1 & 21 & 3 & 2 & 0.655 \\
\hline Donor HLA DR3 & 75.0 & 1 & 20 & 4 & 2 & 0.414 \\
\hline Recipient HLA A26, B38 & 52.8 & 0 & 18 & 0 & 1 & n.d. \\
\hline Recipient HLA A2 & 52.8 & 6 & 2 & 10 & 1 & 0.007 \\
\hline Recipient HLA A11 & 52.8 & 0 & 15 & 3 & 1 & 0.317 \\
\hline Recipient HLA B5 & 52.8 & 0 & 15 & 2 & 2 & 1.000 \\
\hline Recipient HLA B18 & 52.8 & 0 & 16 & 3 & 0 & n.d. \\
\hline Recipient HLA B21 & 52.8 & 0 & 18 & 1 & 0 & n.d. \\
\hline Recipient HLA B35 & 52.8 & 1 & 12 & 4 & 2 & 0.414 \\
\hline Recipient HLA A3 & 52.8 & 1 & 10 & 4 & 4 & 1.000 \\
\hline Recipient HLA DR27 & 52.8 & 0 & 19 & 0 & 0 & n.d. \\
\hline HLA A locus mismatching & 47.2 & 7 & 2 & 3 & 5 & 0.480 \\
\hline HLA B locus mismatching & 47.2 & 10 & 0 & 3 & 4 & 0.706 \\
\hline HLA DR locus mismatching & 47.2 & 12 & 2 & 2 & 1 & 0.564 \\
\hline Anti-thymocyte globulin after Tx & 86.1 & 0 & 30 & 1 & 0 & n.d. \\
\hline Basiliximab therapy after $T x$ & 86.1 & 6 & 11 & 7 & 7 & 1.000 \\
\hline Daclizumab therapy after Tx & 86.1 & 0 & 29 & 1 & 1 & 1.000 \\
\hline Tacrolimus $^{\mathrm{c}}$ after Tx & 100.0 & 5 & 18 & 3 & 10 & 0.052 \\
\hline Ciclosporine $^{c}$ after $T x$ & 100.0 & 17 & 5 & 10 & 4 & 0.109 \\
\hline$M_{M F^{c}}$ after $T x$ & 100.0 & 10 & 15 & 5 & 6 & 0.763 \\
\hline Myfortic $^{C}$ after Tx & 100.0 & 0 & 35 & 0 & 1 & n.d. \\
\hline
\end{tabular}


Table 2 Matched-pair analysis for binominal variables (Continued)

\begin{tabular}{|c|c|c|c|c|c|c|}
\hline Steroids $^{c}$ after $T x$ & 100.0 & 32 & 1 & 1 & 2 & 0.564 \\
\hline Sirolimus ${ }^{\complement}$ after $T x$ & 100.0 & 0 & 34 & 1 & 1 & 1.000 \\
\hline Everolimus $^{c}$ after $T x$ & 100.0 & 0 & 34 & 1 & 1 & 1.000 \\
\hline Azathioprin ${ }^{c}$ after Tx & 100.0 & 1 & 33 & 2 & 0 & 0.157 \\
\hline Tacrolimus at PTLD ${ }^{d}$ & 100.0 & 7 & 14 & 6 & 9 & 0.439 \\
\hline Ciclosporine at PTLD ${ }^{d}$ & 100.0 & 12 & 12 & 9 & 3 & 0.083 \\
\hline CNI-free treatment at PTLD ${ }^{d}$ & 100.0 & 1 & 30 & 1 & 4 & 0.180 \\
\hline
\end{tabular}

Summarized are the results of matched-pair analysis for binominal variables. Their distribution in concordant and discordant pairs in matched-pair analysis is shown

${ }^{\mathrm{a}}(+) /(-)$-classifiers identify yes/no or positive/negative variables

${ }^{\mathrm{b}}$ McNemar's test for binary variables

${ }^{c}$ At hospital discharge

${ }^{\mathrm{d}}$ Diagnosis or equivalent date in the non-PTLD group

$T x$ transplantation, COPD chronic obstructive pulmonary disease, $B M I$ body mass index, EBV Epstein-Barr virus, CMV cytomegalovirus, $H C C$ hepatocellular carcinoma, $H C V$ hepatits $C$ virus, HLA human leukocyte antigen, MMF mycophenolat mofetil, CNI calcineurin inhibitor, n.d. $p$ value not determined due to zero cases within pairs (McNemar's test)

\section{Multivariable regression model for the prediction of PTLD in matched-pair analysis}

The proposed prognostic model for PTLD probability in this matched-pair analysis has been derived with the logit link function of the multivariable binary regression model as:

PTLD probability in $\%=\operatorname{Exp}(y) /(1+\operatorname{Exp}(y))$ with $Y=0.671-1.096 \times$ HLA A2 positive recipient

$+0.151 \times$ tacrolimus dose in $\mathrm{mg}$ at hospital discharge after transplantation $-0.805 \times$ number of episodes of graft rejection

Model fit assessment demonstrated a good model fit $(p=0.483)$. The AUROC was assessed as 0.823 (Fig. 5).

\section{Discussion}

\section{Advantages of the matched-pair approach}

This is the first matched-pair analysis of independent risk factors for PTLD development after kidney or liver transplantation. Matched-pair analysis provides comparatively high levels of evidence for significant findings especially in discordant pairs and in comparatively small sample sizes [45]. The goal of this study is to identify those patients who are at increased risk under comparable clinical conditions in order to provide a rationale for individualized prophylactic measures, intensified screening schemes, and patient information.

The role of risk factors for PTLD was studied independently of age, gender, indication for transplantation, type of transplantation, year of transplantation, and duration of follow-up by using these variables as matching criteria because all of these factors cannot be changed by the treating physician during follow-up. This purposefully chosen matching approach enables the identification of risk factors for PTLD that are independent of these criteria. Some of the identified independent risk factors such as the type and intensity of immunosuppression are under direct control of the treating physician and can thus be altered while other risk factors could be used to decide on increased screening for PTLD.

The setting as 1:1 nearest neighbor matching as compared to a larger matched control is justified due to the fact that poor matches are avoided and an often minimal reduction in power of the statistical analysis is possible [46].

Some of the matching criteria have been described before to influence the risk for PTLD. Patients under the age 10 , as well as patients over 60 years, are more likely to develop PTLD [1, 6-8]. PTLD incidence was reported to be lowest after renal transplantation (1-2\%) and moderate after liver transplantation (3-12\%), compared to much higher observed incidences after intestinal or multiorgan transplantation [47]. Specific indications for liver transplantation such as autoimmune hepatitis, primary biliary cirrhosis, alcoholic cirrhosis, and acute liver failure appear to relate to the risk of PTLD development [5].

This study used the duration of follow-up for matching. This additional matching criterion is essential for the detection of risk factors that are independent of the duration of immunosuppression which is thought to be a critical risk factor for the development of PTLD $[7-9,17-23]$. A very high percentage of patients does perform their follow-up in our transplant center, as there is a defined program for monitoring each patient and their degree of immunosuppression, especially those patients who develop complications are monitored more closely. Without being able to give exact numbers, loss of follow-up is in our opinion not the reason for a rather low PTLD incidence within our center. PLTD incidence in our cohort was $0.86 \%$ which is in line with other reports suggesting a PTLD incidence after liver or kidney transplantation between 1 and $5 \%$ [48].

The occurrence of subsequent re-transplants and the number of subsequent transplants were not significantly different between matched PTLD and non-PTLD cases 
Table 3 Matched-pair analysis for continuous variables

\begin{tabular}{|c|c|c|c|c|c|}
\hline Variable & PTLD mean & Non-PTLD mean & $\begin{array}{l}\text { Mean difference } \\
\text { of Non-PTLD } \\
\text { minus PTLD }\end{array}$ & $p$ value $^{a}$ & $\begin{array}{l}\text { Standard error of } \\
\text { mean difference }\end{array}$ \\
\hline Survival after Tx in years & 7.74 & 9.98 & 2.24 & 0.004 & 0.72 \\
\hline PTLD-free survival in years & 3.99 & 9.98 & 5.99 & $<0.001$ & 0.76 \\
\hline Number of subsequent re-transplants & 0.17 & 0.17 & 0.00 & 1.000 & 0.10 \\
\hline CIT in minutes & 658.07 & 627.07 & -31.00 & 0.756 & 99.05 \\
\hline BMl in $\mathrm{kg} / \mathrm{m}^{2}$ & 20.05 & 20.13 & 0.09 & 0.890 & 0.62 \\
\hline Number of episodes of graft rejection & 0.71 & 1.17 & 0.46 & 0.118 & 0.29 \\
\hline Number of episodes of EBV de novo infections or reactivations & 0.50 & 0.50 & 0.00 & 1.000 & 0.15 \\
\hline Number of episodes of CMV de novo infections or reactivations & 1.47 & 0.75 & -0.72 & 0.042 & 0.34 \\
\hline Duration of pre-Tx dialysis in years & 4.02 & 4.65 & 0.63 & 0.561 & 1.06 \\
\hline Number of HLA A locus recipient-donor mismatches & 0.76 & 0.71 & -0.06 & 0.791 & 0.22 \\
\hline Number of HLA B locus recipient-donor mismatches & 1.12 & 1.06 & -0.06 & 0.805 & 0.23 \\
\hline Number of HLA DR locus recipient-donor mismatches & 0.94 & 1.06 & 0.12 & 0.431 & 0.15 \\
\hline Overall number of HLA recipient-donor mismatches & 2.82 & 2.82 & 0.00 & 1.000 & 0.51 \\
\hline Daily dose of tacrolimus in $\mathrm{mg}^{\mathrm{b}}$ after $\mathrm{Tx}$ & 3.74 & 1.62 & -2.12 & 0.052 & 1.05 \\
\hline Blood level of tacrolimus in $\mathrm{ng} / \mathrm{ml}^{\mathrm{b}}$ after $\mathrm{Tx}$ & 9.97 & 8.13 & -1.83 & 0.734 & 4.69 \\
\hline Daily dose of ciclosporine in $\mathrm{mg}^{\mathrm{b}}$ after $\mathrm{Tx}$ & 176.17 & 183.06 & 6.89 & 0.832 & 32.24 \\
\hline Co blood level of ciclosporine in $\mu \mathrm{g} / \mathrm{l}^{\mathrm{b}}$ after $\mathrm{Tx}$ & 218.46 & 195.91 & -22.55 & 0.230 & 17.63 \\
\hline C2 blood level of ciclosporine in $\mu \mathrm{g} / \mathrm{l}^{\mathrm{b}}$ after $\mathrm{Tx}$ & 1183.0 & 1168.5 & -14.5 & 0.909 & 100.5 \\
\hline Daily dose of MMF in mg after ${ }^{\mathrm{b}}$ after Tx & 545.00 & 551.67 & 6.67 & 0.967 & 161.43 \\
\hline Daily dose of prednisolone in $\mathrm{mg}^{\mathrm{b}}$ after $\mathrm{Tx}$ & 11.13 & 10.99 & -0.14 & 0.916 & 1.31 \\
\hline Daily dose of sirolimus in ${ }^{\mathrm{b}}$ after $T x$ & 0.06 & 0.06 & 0.00 & 1.000 & 0.08 \\
\hline Daily dose of everolimus in $\mathrm{mg}^{\mathrm{b}}$ after $\mathrm{Tx}$ & 0.06 & 0.14 & 0.08 & 0.585 & 0.15 \\
\hline Daily dose of azathioprine in $\mathrm{mg}^{\mathrm{b}}$ after $\mathrm{Tx}$ & 2.08 & 2.78 & 0.69 & 0.160 & 0.48 \\
\hline Tacrolimus treatment in months ${ }^{c}$ & 12.47 & 15.62 & 3.15 & 0.596 & 5.87 \\
\hline Tacrolimus treatment in \% of time of immunosuppression ${ }^{c}$ & 46.87 & 33.45 & -13.42 & 0.231 & 11.00 \\
\hline Ciclosporine treatment in months ${ }^{c}$ & 27.16 & 25.58 & -1.58 & 0.737 & 4.67 \\
\hline Ciclosporine treatment in $\%$ of time of immunosuppression ${ }^{c}$ & 46.25 & 59.70 & 13.45 & 0.180 & 9.83 \\
\hline $\mathrm{CNI}^{- \text {free treatment in months }}{ }^{c}$ & 6.96 & 5.29 & -1.67 & 0.628 & 3.41 \\
\hline $\mathrm{CNI}$-free treatment in \% of time of immunosuppression ${ }^{c}$ & 7.81 & 6.69 & -1.11 & 0.803 & 4.42 \\
\hline
\end{tabular}

Shown are the results of univariable matched-pair analysis for continuous variables

${ }^{\text {a Paired } t \text { test }}$

${ }^{\mathrm{b}}$ At hospital discharge

'Until PTLD diagnosis or equivalent date in the non-PTLD group)

Tx transplantation, CIT cold ischemic time, BMI body mass index, EBV Epstein-Barr virus, CMV cytomegalovirus, HLA human leukocyte antigen, CO trough blood

level, $C 2$ blood level 2 hours after oral intake, MMF mycophenolat mofetil, CNI calcineurin inhibitor

$(p=0.739$, McNemar's test and $p=1.000$, paired $t$ test, respectively). Therefore, the above described consideration of donor and recipient HLA status at PTLD diagnosis or the equivalent time point during follow-up in their corresponding matching partner appears justified.

\section{Worse survival of patients with PTLD}

Long-term survival after transplantation was significantly shorter in the analyzed PTLD patients as compared to the non-PTLD matching partners $(p=0.004)$. This finding confirms the clinical relevance of PTLD for long-term prognosis after transplantation which is known to be a serious and life-threatening complication after solid-organ transplantation [4].

\section{CMV and EBV are risk factors for PTLD}

This matched-pair study revealed that patients with PTLD had significantly more episodes of cytomegalovirus (CMV) de novo infections or reactivations as compared to their non-PTLD matching partners. This result corresponds to other studies that found coexisting CMV infection as a potential risk factor for PTLD [7, 35, 36]. 


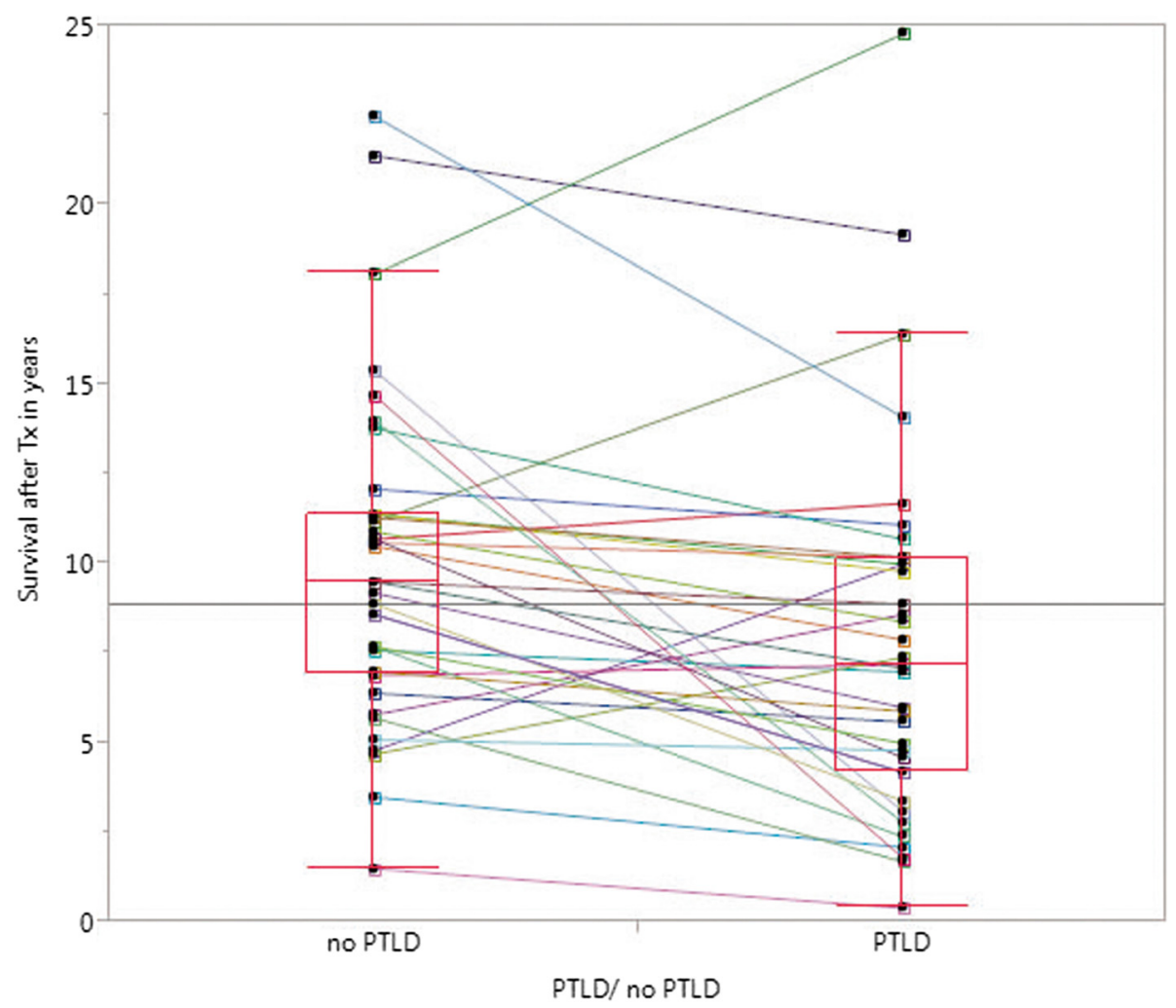

Fig. 2 Shown are the results of matched-pair analysis for patient survival after transplantation ( $p=0.004$; paired $t$ test). The colored lines link values between PTLD patients and matching non-PTLD partners, demonstrating the difference in each pair. Tx transplantation

Immunosuppressive therapy promotes a low control of CMV which has been shown to interfere with the immune system in vivo and in vitro [36, 49,50]. Also, a strong association between CMV reactivation and EBV reactivation has been demonstrated in a study from Zallio et al. [51]. Thus, closer monitoring for CMV activity as well as the role of antiviral prophylaxis after transplantation should not be underestimated. This approach should be considered even in CMV IgG-positive patients as they may reduce the PTLD incidence after transplantation.

Treatment after transplantation with antiviral agents, such as ganciclovir, valganciclovir, or aciclovir, for which prevention of EBV-related PTLD development has been suggested [1,31,34], did not show a statistically significant effect on the occurrence of PTLD in this study. We conclude that antiviral prophylaxis may be ineffective for the prevention of PTLD or, alternatively, was not consistently enough or not long enough applied in the investigated cohort to enable a significant protective effect in PTLD cases. Ganciclovir and valganciclovir are nucleoside analogues that inhibit EBV DNA replication. In cells that are latently infected with EBV and cells of EBV-driven lymphomas, these antiviral agents appear to be ineffective due to a lack of an activating thymidine kinase [47].
EBV-seronegative patients were reported in a nonmatched analysis to have a 4.7-fold higher hazard ratio for PTLD as compared to EBV-seropositive recipients due to increased EBV infection risks [30]. However, in the current analysis, the frequency of the recipients' positive EBV IgG status at transplantation was not significantly different between matching PTLD and nonPTLD partners (Table 2).

It is striking that this first matched-pair analysis did not find a significant risk for PTLD that is associated with the occurrence and number of EBV infections or reactivations after transplantation during follow-up independent of age at transplantation.

However, all analyzed PTLD cases with available data on EBV latent membrane protein or EBV-encoded RNA in tumor cells (26 cases of 36 cases) were positive for EBV in the histology specimen (Table 1). All 31 PTLD cases with available data on EBV IgG positivity or EBV DNA positivity at the time of PTLD diagnosis were either EBV IgG or EBV DNA positive at the time of PTLD diagnosis (Table 1).

These findings support the previously described strong risk for PTLD which is associated with EBV infections and reactivations even though the current matched-pair analysis did not reveal a significant statistical difference 


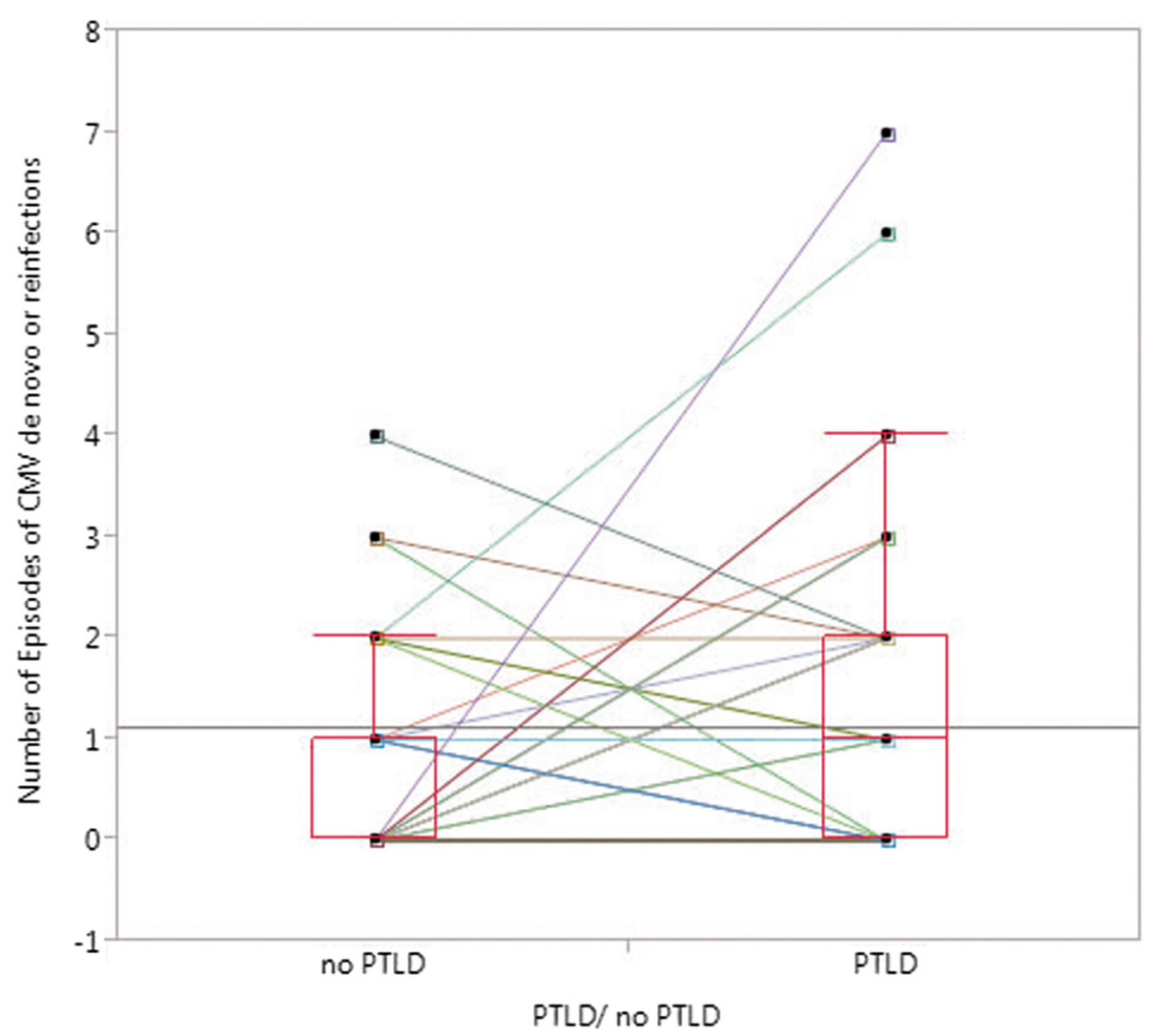

Fig. 3 Shown are the results of matched-pair analysis for the number of episodes of CMV de novo infections or reactivations ( $p=0.042$; paired $t$ test). The colored lines link values between PTLD patients and matching non-PTLD partners, demonstrating the difference in each pair. Tx transplantation, CMV cytomegalovirus

in the number of EBV infections or reactivation episodes after transplantation between PTLD and matched nonPTLD cases (Table 3). We believe that this somehow contradictory observation may be due to the fact that EBV infections and reactivations were frequently not detected during follow-up due to subclinical symptoms. This assumption supports the recommendation that EBV serology and EBV viral load should be monitored on a regular basis [52].

\section{Type of immunosuppression is relevant for PTLD risk}

Many authors noted that the type of immunosuppression, as well the degree of immunosuppression influences the risk of PTLD [7-9, 17-23]. This matched-pair analysis confirms that initial tacrolimus-based immunosuppression after transplantation as well as high daily doses of tacrolimus after transplantation both increased the risk of later PTLD development. This corresponds to other reports that described a two- to fivefold increase of PTLD risk with tacrolimus instead of ciclosporine after pediatric and adult solid-organ transplantation $[8,53,54]$.
Interestingly, immunosuppressive induction therapy, either with basiliximab, daclizumab, or anti-thymocyte globulin (ATG), did not increase or decrease the risk of PTLD development in the setting of this analysis. This finding is based on the fact that no discordant pairs were found where the PTLD case has received induction immunosuppression either with anti-thymocyte globulin, basiliximab, or daclizumab while his or her matching partner did not (Table 2).

The same non-significant result was detected for immunosuppressive blood levels. Neither for tacrolimus nor for ciclosporine blood levels $(\mathrm{C} 0, \mathrm{C} 2)$ at hospital discharge, a significant difference between PTLD patients and matched non-PTLD controls could be detected in this study. One explanation could be that none of these blood levels reflect the actual peak drug level which might be the crucial factor for turning cells at risk to dedifferentiate into malignant lymphoma cells.

It is possible that other parameters such as the area under the time curve (AUC) of calcineurin-inhibitor (CNI) blood levels, which is known to be the biologically relevant parameter for toxicity and the immunosuppressive effect of these agents $[55,56]$, rather than trough blood levels may 


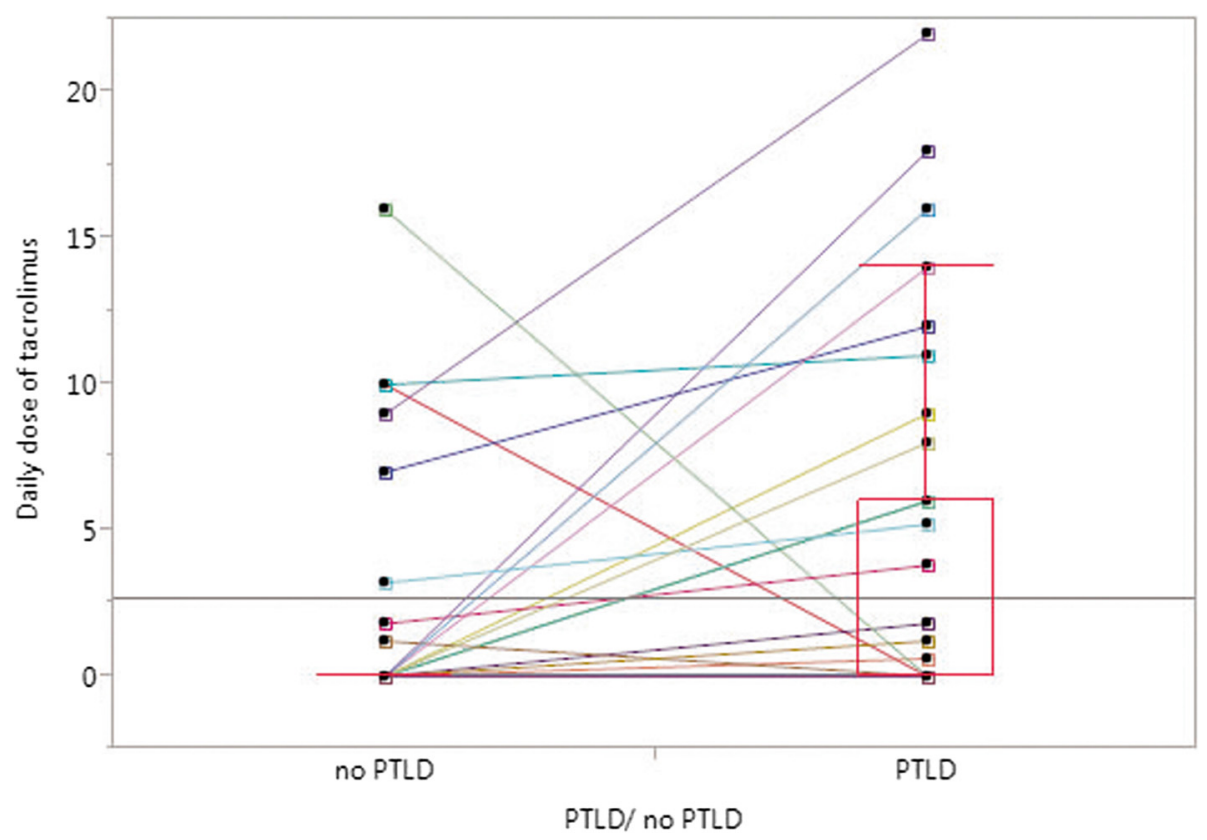

Fig. 4 Shown are the results of matched-pair analysis for daily dosages of tacrolimus at hospital discharge after transplantation ( $p=0.052$; paired $t$ test). The colored lines link values between PTLD patients and matching non-PTLD partners, demonstrating the difference in each pair. Tx transplantation

be more relevant for the development of de novo malignancy. Further, inter-individual differences concerning the first pass metabolism in immunosuppressed patients vary relative to CNI-absorption and thus blood levels $[57,58]$. These assumptions may explain to some degree the perceived discrepancy between the observed effects of immunosuppressive dosages on PTLD risk while the respective blood drug levels appeared to be less important.

Further analysis of the duration of treatment with tacrolimus in months as well as in percent of the time until PTLD diagnosis or the equivalent time frame for the nonPTLD matching partners did not reveal a statistically significant difference between PTLD and non-PTLD patients. Similar analyses for the treatment with ciclosporine or calcineurin-inhibitor (CNI)-free immunosuppression during follow-up demonstrated the same non-significant results (Table 3). We believe that analyses of the complete immunosuppression in each individual, including all changes of dosing and all blood level changes over time during follow-up, are required for deeper insights into the long-term consequences of immunosuppression. Dosages in children are usually adapted to their body weight or body surface and blood levels. Nevertheless, we believe that analysis of absolute dosages in combination with blood levels in this study provides reasonable results due to the tight matching for age and duration of follow-up in matched-pair analysis.
The duration of immunosuppression could not be identified as a prognostic variable for PTLD development in this study, because the duration of follow-up after transplantation was used as one of the matching criteria.

\section{The role of graft rejection and HLA haplotypes}

The number of graft rejection episodes appeared to be an independent significant risk factor in multivariable analysis $(p=0.023)$ with higher numbers of graft rejection episodes protecting patients from PTLD $(\mathrm{OR}=0.38)$ which can be explained by lower intensity of immunosuppressive therapy. The likelihood of rejection episodes decreased significantly with higher percentages of time on tacrolimus-based immunosuppression during followup ( $p=0.015$, logistic regression) which is in line with previous reports in the literature [59]. This study showed that lower numbers of graft rejection episodes were linked to a higher risk for PTLD, and at the same time, lower numbers of graft rejection episodes were linked to tacrolimus-based immunosuppression reinforcing the finding that tacrolimus dosage at hospital discharge increased the risk of PTLD development. Therefore, patients on tacrolimus with none or few rejection episodes might benefit from closer monitoring for PTLD during follow-up.

HLA A2 haplotype in transplant recipients was a protective factor in this study instead of increasing the risk for PTLD as was reported previously $[11,12]$. HLA A2 


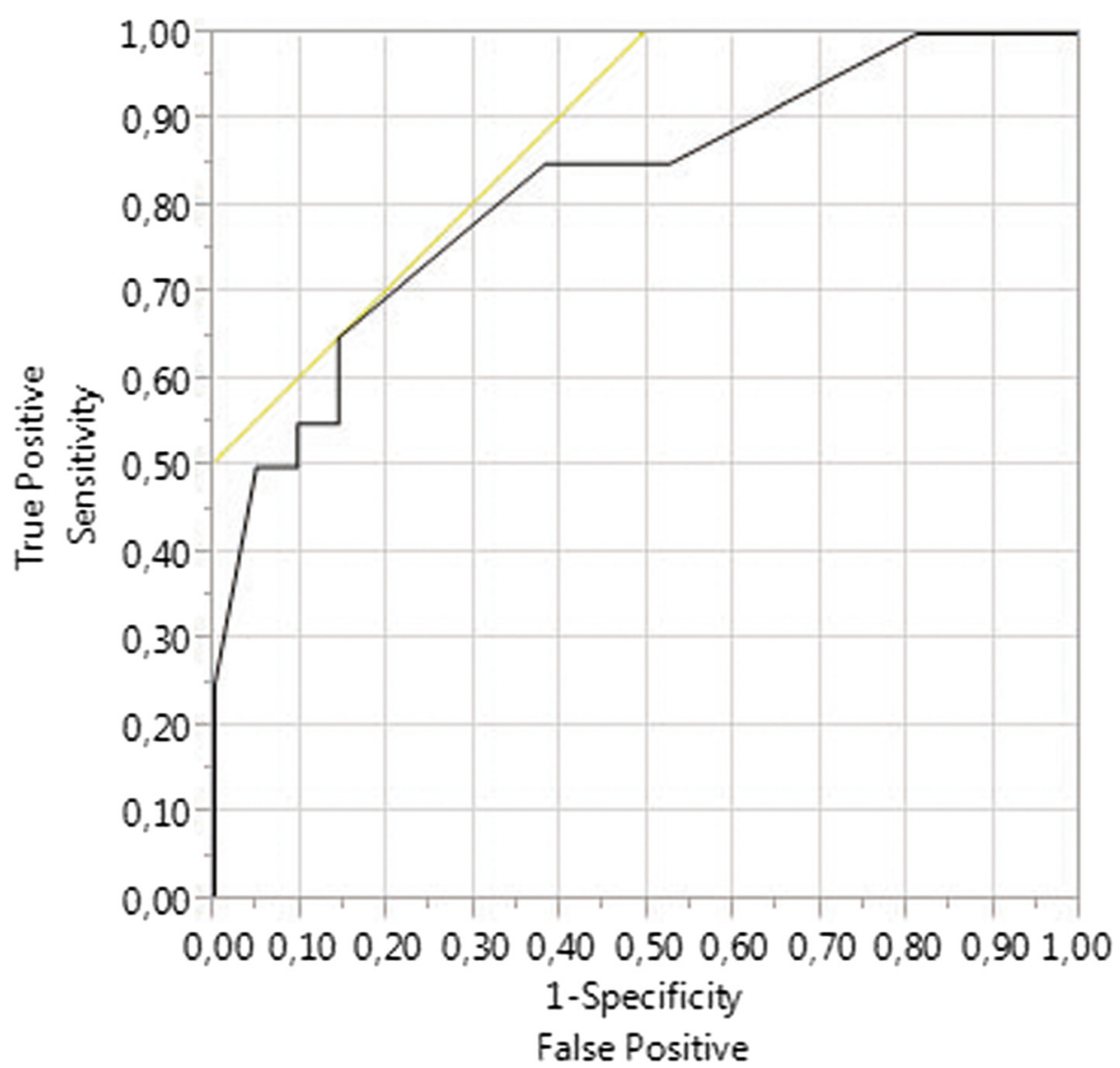

Fig. 5 Shown is the result of ROC-curve analysis of the multivariable logistic regression model for the prediction of PTLD in matched-pair analysis (AUROC: 0.823 ) indicating a good discriminative power as well as good overall model correctness and thus potential clinical usefulness provided that the matched-pair criteria are met

haplotype encodes a HLA class I protein which presents peptides from expired or defective intracellular proteins as well as proteins from invasive viruses from within the cell to the T cell receptor on CD8+, often cytotoxic, T cells in order to destroy the (infected) cell [60]. The result of our study together with previously published findings suggests that HLA A2 haplotype might be responsible for an effective presentation of EBV antigens to CD8+ cytotoxic $\mathrm{T}$ cells and thus that HLA A2-positive individuals may control EBV infection better than negative counterparts [61]. The identification that lack of HLA A2 in the recipient is significantly associated with PTLD is hypothesis generating and should be a basis for larger studies.

Further analysis revealed that the percentage of tacrolimus-based immunosuppression during followup and the dosage of tacrolimus at hospital discharge were not related to HLA A2 positivity $(p=0.169$ and $p=0.167$, respectively). This finding excludes the possibility that HLA A2 positivity is a surrogate marker for more or less intense immunosuppression.

All other HLA types and possible donor-recipient HLA mismatching combinations which have been previously described as either protective or as risk factors for PTLD development $[1,4,13-16]$ did not show any significant influence on PTLD development in this matched-pair analysis. Previous reports did not apply a matched-pair approach. However, this observation is limited by the fact that not for all liver-transplanted patients the HLA status was given and thus taken into account (Table 2).

\section{Multivariable risk factor analysis}

Conditional multivariable regression revealed recipient HLA A2 haplotype, the level of tacrolimus dosage at hospital discharge after transplantation, and the number of graft rejection episodes as independent risk factors for the development of PTLD, provided that the aforementioned matching criteria are met. Addition of the number of CMV infections or reactivations after transplantation as an easily trackable factor to the derived multivariable prediction model did not improve the model while revealing a statistically non-significant influence in multivariable regression. Therefore, we have eliminated this variable from the final prediction model. 
The non-significant result of the model fit assessment ( $p=0.483$ ) excluded the possibility of overfitting, and the AUROC (0.823) of the derived predictive model indicated a good discriminative power as well as good overall model correctness, and thus potential clinical usefulness [43, 44]. It allows an early identification of patients at increased risk for PTLD. We accept that the limitations of the proposed predictive model include the relatively small number of analyzed cases and a lack of external validation with data from another transplant center. The proposed model should therefore be regarded cautiously.

\section{Limitations}

The limitations of this work mostly refer to the limited number of PTLD cases in a single-center study and its retrospective nature. Despite the design of this study as matched-pair analysis and the introduction of several substantial matching criteria, individual differences in patients still contribute to some uncertainty. A larger, prospective, multicenter trial will be necessary to define risk factors for PTLD development and to refine screening methods based on more substantial findings. Caution in the clinical application of the derived prognostic model is warranted due to its current lack of external validation.

\section{Conclusions}

This study shows that the most likely scenario for the development of PTLD is caused by high tacrolimus dosages at hospital discharge, fewer subsequent rejection episodes which are associated with higher percentages of time on tacrolimus treatment during follow-up, absent HLA A2 haplotype in the recipient, and CMV infections or reactivations during follow-up. EBV-related PTLD risk could not be quantified adequately in this study while all investigated tumors were EBV positive. Patients with unfavorable combinations of risk factors should be monitored more closely for PTLD and their EBV status.

\begin{abstract}
Abbreviations
$95 \% \mathrm{Cl}, 95 \%$ confidence interval; ADPKD, autosomal dominant polycystic disease; ATG, anti-thymocyte globulin; AUROC, area under ROC-curve; BMI, body mass index; C0, trough blood level; C2, blood level 2 hours after oral intake; CIT, cold ischemic time; CMV, cytomegalovirus; CNI, calcineurininhibitor; CNS, central nervous system; COPD, chronic obstructive pulmonary disease; EBV, Epstein-Barr virus; GN, glomerulonephritis; HCC, hepatocellular carcinoma; HCV, hepatits C virus; HHV-8, human herpes virus 8; HLA, human leukocyte antigen; HUS, hemolytic-uremic syndrome; Ig, immunoglobulin; MMF, mycophenolat mofetil; n.d., not determined; No., number; OR, odds ratio; PSC, primary sclerosing cholangitis; PTLD, post-transplant lymphoproliferative disorder; ROC, receiver operating characteristic; Tx, transplantation
\end{abstract}

\section{Acknowledgements}

The authors declare that they have no acknowledgements to make.

\section{Funding}

This work was supported by a grant from the German Federal Ministry of Education and Research (reference number: 01E01302).

\section{Availability of data and materials}

We do not wish to share our data, because informed consent could not be obtained from all patients for publication of the raw data supporting the findings in this study due to the retrospective nature of the investigation and due to the fact that some patients have already died.

\section{Authors' contributions}

$L R$ contributed to the refinement of the study design, performed the data collection and data analysis, and wrote the manuscript. CK contributed to the study design, provided the oncological expert input and critical appraisal, and helped in writing the manuscript. HK approved the study design and data analysis and provided the statistical expert input. AK contributed to the critical appraisal and revision of the manuscript draft. $N E_{\text {, }}$ $L P, F L, V A$, and UB contributed to the clinical expert input, critical appraisal, and manuscript revision. HS proposed the initial study design and helped in performing the data analysis and writing the manuscript. All authors read and approved the final manuscript.

\section{Competing interests}

The authors declare that they have no competing interests.

\section{Consent for publication}

Not applicable.

\section{Ethics approval and consent to participate}

This retrospective study was approved by the Ethics Committee of Hannover Medical School (approval decision number 2375-2014) stating that as an observational retrospective study, according to the Professional Code of the German Medical Association (article B.III. § 15.1), neither informed consent nor approval of the ethics committee was needed for this study. Patients provided informed consent that their data may be used for scientific purposes at the time of hospital admission which is the general policy of our institution but they did not provide informed consent to the publication of their raw data. Patient records and patient data were anonymized and de-identified prior to analysis.

\section{Author details}

${ }^{1}$ Core Facility Quality Management \& Health Technology Assessment in Transplantation, Integrated Research and Treatment Center Transplantation (IFB-Tx), Hannover Medical School, Hannover, Germany. ${ }^{2}$ Hematology, Hemostasis, Oncology and Stem Cell Transplantation, Hannover Medical School, Hannover, Germany. ${ }^{3}$ Trauma and Orthopedic Surgery, Federal Armed Forces Hospital Westerstede, Westerstede, Germany. ${ }^{4}$ General, Visceral and Transplant Surgery, Hannover Medical School, Carl-Neuberg-Str. 1, 30625 Hannover, Germany. ${ }^{5}$ Pediatric Nephrology, Hepatology and Metabolic Disorders, Hannover Medical School, Hannover, Germany. ${ }^{6}$ Nephrology, Hannover Medical School, Hannover, Germany.

Received: 14 March 2016 Accepted: 24 July 2016

Published online: 02 August 2016

\section{References}

1. Al-Mansour Z, Nelson BP, Evens AM. Post-transplant lymphoproliferative disease (PTLD): risk factors, diagnosis, and current treatment strategies. Curr Hematol Malig Rep. 2013;8:173-83.

2. Hanto DW, Frizzera G, Peczalska KJ, et al. Epstein-Barr virus, immunodeficiency, and B cell lymphoproliferation. Transplantation. 1985;39:461.

3. So S. CMV and EBV-PTLD after liver transplantation. Transplant Proc. 2001;33: 1317-9.

4. Mucha K, Foroncewicz B, Ziarkiewicz-Wróblewska B, Krawczyk M, Lerut J, Pączek L. Post-transplant lymphoproliferative disorder in view of the new WHO classification: a more rational approach to a protean disease? Nephrol Dial Transplant. 2010;25:2089-98.

5. Hartmann C, Schuchmann M, Zimmermann T. Posttransplant lymphoproliferative disease in liver transplant patients. Curr Infect Dis Rep. 2011;13:53-9.

6. Cox KL, Lawrence-Miyasaki LS, Garcia-Kennedy R, et al. An increased incidence of Epstein-Barr virus infection and lymphoproliferative disorder in young children on FK506 after liver transplantation. Transplantation. 1995; 59(4):524. 
7. Dharnidharka VR, Sullivan EK, Stablein DM, Tejani AH. HarmonWE. North American Pediatric Renal Transplant Cooperative S. Risk factors for posttransplant lymphoproliferative disorder (PTLD) in pediatric kidney transplantation: a report of the North American Pediatric Renal Transplant Cooperative Study (NAPRTCS). Transplantation. 2001;71(8): 1065-8.

8. Opelz G, Dohler B. Lymphomas after solid organ transplantation: a collaborative transplant study report. Am J Transplant. 2004;4(2):222-30.

9. Caillard S, Dharnidharka V, Agodoa L, Bohen E, Abbott K. Posttransplant lymphoproliferative disorders after renal transplantation in the United States in era of modern immunosuppression. Transplantation. 2005;80(9): $1233-43$.

10. Nee R, Hurst FP, Dharnidharka VR, Jindal RM, Agodoa LY, Abbott KC. Racial variation in the development of posttransplant lymphoproliferative disorders after renal transplantation. Transplantation. 2011;92(2):190-5.

11. Subklewe M, Marquis $R$, Choquet $S$, et al. Association of human leukocyte antigen haplotypes with posttransplant lymphoproliferative disease after solid organ transplantation. Transplantation. 2006;82(8):1093-100.

12. Pourfarziani V, Einollahi B, Taheri S, Nemati E, Nafar M, Kalantar E. Associations of human leukocyte antigen (HLA) haplotypes with risk of developing lymphoproliferative disorders after renal transplantation. Ann Transplant. 2007;12(4):16-22.

13. Lustberg ME, Pelletier RP, Porcu P, et al. Human leukocyte antigen type and posttransplant lymphoproliferative disorder. Transplantation. 2015;99(6):1220-5. doi:10.1097/TP.

14. Bakker NA, van Imhoff GW, Verschuuren EA, et al. HLA antigens and post renal transplant lymphoproliferative disease: HLA-B matching is critical. Transplantation. 2005;80(5):595-9.

15. Reshef $R$, Luskin MR, Kamoun M, et al. Association of HLA polymorphisms with post-transplant lymphoproliferative disorder in solid-organ transplant recipients. Am J Transplant. 2011;11(4):817-25.

16. Végső $G$, Hajdu M, Sebestyén A. Lymphoproliferative disorders after solid organ transplantation-classification, incidence, risk factors, early detection and treatment options. Pathol Oncol Res. 2011;17:443-54.

17. Opelz G, Henderson R. Incidence of non-Hodgkin lymphoma in kidney and heart transplant recipients. Lancet. 1993;342(8886-8887):1514-6.

18. Cockfield SM. Identifying the patient at risk for post-transplant lymphoproliferative disorder. Transpl Infect Dis. 2001;3(2):70-8

19. Birkeland SA, Hamilton-Dutoit S. Is posttransplant lymphoproliferative disorder (PTLD) caused by any specific immunosuppressive drug or by the transplantation per se? Transplantation. 2003;76:984.

20. Schubert S, Renner C, Hammer M, et al. Relationship of immunosuppression to Epstein-Barr viral load and lymphoproliferative disease in pediatric heart transplant patients. J Heart Lung Transplant. 2008;27:100.

21. Parker A, Bowles K, Bradley JA, et al. Diagnosis of post-transplant lymphoproliferative disorder in solid organ transplant recipients-BCSH and BTS guidelines. Br J Haematol. 2010;149:675.

22. Jagadeesh D, Woda BA, Draper J, Evens AM. Posttransplant lymphoproliferative disorders: risk, classification, and therapeutic recommendations. Curr Treat Options in Oncol. 2012;13(1):122-36.

23. Schober T, Framke $\mathrm{T}$, Kreipe $\mathrm{H}$, et al. Characteristics of early and late PTLD development in pediatric solid organ transplant recipients. Transplantation. 2013;95:240Y246

24. Paya CV, Fung JJ, Nalesnik MA, et al. Epstein-Barr virus-induced posttransplant lymphoproliferative disorders. ASTS/ASTP EBV-PTLD Task Force and The Mayo Clinic Organized International Consensus Development Meeting. Transplantation. 1999;68(10):1517-25.

25. Loren AW, Porter DL, Stadtmauer EA, Tsai DE. Post-transplant lymphoproliferative disorder: a review. Bone Marrow Transplant. 2003;31(3):145-55.

26. Johnson LR, Nalesnik MA, Swerdlow SH. Impact of Epstein-Barr virus in monomorphic B cell posttransplant lymphoproliferative disorders: a histogenetic study. Am J Surg Pathol. 2006;30(12):1604-12.

27. Novoa-Takara L, Perkins SL, Qi D, et al. Histogenetic phenotypes of B cells in posttransplant lymphoproliferative disorders by immunohistochemical analysis correlate with transplant type: solid organ vs hematopoietic stem cell transplantation. Am J Clin Pathol. 2005;123(1):104-12.

28. Oton $A B$, Wang $H$, Leleu $X$, et al. Clinical and pathological prognostic markers for survival in adult patients with post-transplant lymphoproliferative disorders in solid transplant. Leuk Lymphoma. 2008; 49(9):1738-44
29. Nourse JP, Jones K, Gandhi MK. Epstein-Barr virus-related posttransplant lymphoproliferative disorders: pathogenetic insights for targeted therapy. Am J Transplant. 2011;11(5):888-95.

30. McDonald RA, Smith JM, Ho M, et al. Incidence of PTLD in pediatric renal transplant recipients receiving basiliximab, calcineurin inhibitor, sirolimus and steroids. Am J Transplant. 2008;8(5):984-9.

31. Rooney CM, Smith CA, Ng CY, et al. Use of gene-modified virus-specific T lymphocytes to control Epstein-Barr-virus-related lymphoproliferation. Lancet. 1995;345(8941):9-13.

32. Nalesnik MA, Rao AS, Furukawa H, et al. Autologous lymphokine-activated killer cell therapy of Epstein-Barr virus-positive and -negative lymphoproliferative disorders arising in organ transplant recipients. Transplantation. 1997;63(9):1200-5.

33. Afshar K, Rao AP, Patel V, Forrester K, Ganesh S. Use of Foscarnet therapy for EBV infection following control of PTLD with enhancement of cellular immunity in a lung-transplant recipient; Transplantation. 2011; Article ID 919651, doi:10.1155/2011/919651.

34. Höcker B, Böhm S, Fickenscher H, et al. (Val-)Ganciclovir prophylaxis reduces Epstein-Barr virus primary infection in pediatric renal transplantation. Transpl Int. 2012;25(7):723-31.

35. Walker RC, Marshall WF, Strickler JG, et al. Pretransplantation assessment of the risk of lymphoproliferative disorder. Clin Infect Dis. 1995;20(5):1346.

36. Manez R, Breinig MC, Linden P, et al. Posttransplant lymphoproliferative disease in primary Epstein-Barr virus infection after liver transplantation: the role of cytomegalovirus disease. J Infect Dis. 1997;176(6):1462.

37. Gao SZ, Chaparro SV, Perlroth M, et al. Post-transplantion lymphoproliferative disease in heart-lung transplant recipients: 30-year experience at Stanford University. J Heart Lung Transplant. 2003;22:505.

38. Opelz G, Daniel V, Naujokat C, et al. Effect of cytomegalovirus prophylaxis with immunoglobulin or with antiviral drugs on posttransplant nonHodgkin lymphoma: a multicentre retrospective analysis. Lancet Oncol. 2007;8:212-8.

39. Buda A, Caforio A, Calabrese F, et al. Lymphoproliferative disorders in heart transplant recipients: role of hepatitis C virus (HCV) and Epstein-Barr virus (EBV) infection. Transplant Int. 2000;13 Suppl 1:\$402-5.

40. Tsao L, Hsi ED. The clinicopathologic spectrum of posttransplantation lymphoproliferative disorders. Arch Pathol Lab Med. 2007;131(8):1209-18.

41. Beimler J, Zeier M. Borderline rejection after renal transplantation-to treat or not to treat. Clin Transplant. 2009;23 Suppl 21:19-25.

42. Agresti A. Categorial data analysis. Hoboken: Jon Wiley \& Sons, Inc.; 2013. p. $418-24$

43. Hanley JA, McNeil BJ. The meaning and use of the area under a receiver operating characteristic (ROC) curve. Radiology. 1982;143:29-36.

44. Schrem $H$, Reichert $M$, Reichert $B$, et al. Value of the SOFA score as a predictive model for short-term survival in high-risk liver transplant recipients with a pre-transplant labMELD score $\geq 30$. Langenbecks Arch Surg. 2012;397:717-26.

45. Breslow NE, Day NE. Statistical methods in cancer research volume 1-the analysis of case-control studies. IARC Scientific Publications No. 32. Lyon: International Agency for Research on Cancer; 1980. p. 161-89. re-impression 2000 .

46. Stuart EA. Matching methods for causal inference: a review and a look forward. Stat Sci. 2010;25(1):1-21. doi:10.1214/09-STS313.

47. Murukesan V, Mukherjee S. Managing post-transplant lymphoproliferative disorders in solid-organ transplant recipients: a review of immunosuppressant regimens. Drugs. 2012;72(12):1631-43.

48. Bakker NA, van Imhoff GW, Verschuuren EA, et al. Early onset posttransplant lymphoproliferative disease is associated with allograft localization. Clin Transplant. 2005;3:327-34.

49. Miller-Kittrell M, Sparer TE. Feeling manipulated: cytomegalovirus immune manipulation. Virol J. 2009;6:4.

50. La Rosa C, Diamond DJ. The immune response to human CMV. Futur Virol. 2012;7(3):279-93.

51. Zallio F, Primon V, Tamiazzo S, et al. Epstein-Barr virus reactivation in allogeneic stem cell transplantation is highly related to cytomegalovirus reactivation. Clin Transplant. 2013;27(4):E491-7.

52. Gulley ML, Tang W. Using Epstein-Barr viral load assays to diagnose, monitor, and prevent posttransplant lymphoproliferative disorder. Clin Microbiol Rev. 2010;23(2):350-66.

53. Cao S, Cox KL, Berquist W, et al. Long-term outcomes in pediatric liver recipients: comparison between cyclosporin $\mathrm{A}$ and tacrolimus. Pediatr Transplantation. 1999;3:22-6. 
54. Younes BS, McDiarmid SV, Martin MG, et al. The effect of immunosuppression on posttransplant lymphoproliferative disease in pediatric liver transplant patients. Transplantation. 2000;70(1):94-9.

55. Villamil F, Pollard S. C2 monitoring of cyclosporine in de novo liver transplant recipients: the clinician's perspective. Liver Transpl. 2004;10:577-83.

56. Schrem H, Lück R, Becker T, Nashan B, Klempnauer J. Update on liver transplantation using cyclosporine. Transplant Proc. 2004;36:2525-31.

57. Keown PA. New concepts in cyclosporine monitoring. Curr Opin Nephrol Hypertens. 2002;11:619-26.

58. de Jonge $H$, Naesens $M$, Kuypers DR. New insights into the pharmacokinetics and pharmacodynamics of the calcineurin inhibitors and mycophenolic acid: possible consequences for therapeutic drug monitoring in solid organ transplantation. Ther Drug Monit. 2009;31:416-35.

59. Molnar AO, Fergusson D, Tsampalieros AK, et al. Generic immunosuppression in solid organ transplantation: systematic review and meta-analysis. BMJ. 2015;350:h3163. doi:10.1136/bmj.h3163.

60. Mosaad YM. Clinical role of human leukocyte antigen in health and disease. Scand J Immunol. 2015;82(4):283-306.

61. McAulay KA, Jarrett RF. Human leukocyte antigens and genetic susceptibility to lymphoma. Tissue Antigens. 2015;86(2):98-113.

Submit your next manuscript to BioMed Central and we will help you at every step:

- We accept pre-submission inquiries

- Our selector tool helps you to find the most relevant journal

- We provide round the clock customer support

- Convenient online submission

- Thorough peer review

- Inclusion in PubMed and all major indexing services

- Maximum visibility for your research

Submit your manuscript at www.biomedcentral.com/submit
Biomed Central 